\title{
Epidemiology and detection of HIV-1 among pregnant women in the United Kingdom: results from national surveillance 1988-96
}

\author{
Angus Nicoll, Christine McGarrigle, Anthony R Brady, A E Ades, Pat Tookey, Trinh Duong, \\ Janet Mortimer, Susan Cliffe, David Goldberg, David Tappin, Chris Hudson and Catherine Peckham \\ for the principal collaborators
}

\begin{abstract}
Objective: To describe the epidemiology of HIV-1 infection in pregnant women in the United Kingdom.

Design: Serial unlinked serosurveillance for HIV-1 in neonatal specimens and surveillance through registers of diagnosed maternal and paediatric infections from reporting by obstetricians, paediatricians, and microbiologists.

Setting: United Kingdom, 1988-96.

Subjects: Pregnant women proceeding to live births and their children

Main outcome measures: Time trends in prevalence of HIV-1 seropositivity in newborn infants (as a proxy for infection in mothers); the proportions of mothers with diagnosed HIV-1 infections, and their characteristics.

Results: HIV-1 prevalence among mothers in London rose sixfold between 1988 and 1996 (0.19\% of women tested; 1 in 520 in 1996). Apart from in Edinburgh and Dundee, levels remained low in Scotland $(0.025 \% ; 1$ in 3970) and elsewhere in the United Kingdom $(0.016 \%$; 1 in 1930). Over a third of births to infected mothers in 1996 occurred outside London. In London the reported infections were predominantly among black African women, whereas in Scotland most were associated with drug injecting. The contribution of reported infection among African women increased over time as that of drug injecting declined. In Scotland 51\% of mothers' infections were diagnosed before the birth. In England, despite a national policy initiative in 1992 to increase the antenatal detection rate of HIV, no improvement in detection was observed, and in 1996 only $15 \%$ of previously unrecognised HIV infections were diagnosed during pregnancy.

Conclusions: HIV-1 infection affects mothers throughout the United Kingdom but is most common in London. Levels of diagnosis in pregnant women have not improved. Surveillance data can monitor effectively the impact of initiatives to reduce preventable HIV-1 infections in children.
\end{abstract}

\section{Introduction}

Information about infection with human immunodeficiency virus among pregnant women is important for public health, obstetrics, and paediatrics. Time trends in maternal prevalence reflect the general prevalence of HIV infection, ${ }^{1}$ and description of the characteristics of infected women whose children develop AIDS has informed the targeting of sexual health promotion and HIV testing. ${ }^{23}$ In well resourced countries the numbers of vertically acquired HIV infections can be reduced greatly, but effective intervention programmes depend on diagnosis of the mother's infection before the baby's birth. ${ }^{5}$ Since 1992 it has been policy in the United Kingdom to offer every pregnant woman voluntary confidential antenatal HIV testing wherever maternal HIV prevalence is high, and elsewhere to offer testing to women at increased risk. ${ }^{67}$ We investigated time trends in the prevalence of HIV-1 infection in the United Kingdom in the mothers of newborn babies through unlinked testing of heel prick blood specimens. ${ }^{8}$ We also describe characteristics of mothers reported to have been diagnosed as infected with HIV (surveillance data) and give the proportions of all HIV-1 infections in pregnant women accounted for by these data.

\section{Methods}

Data are presented for births in the United Kingdom in the period 1988 to 1996; sources are given below. Primary analyses were based on maternal residence in three recognised geographical divisions: London, Scotland, and the rest of the United Kingdom. These coincide with the distribution of the two major routes for HIV infection of women with AIDS in the United Kingdom: heterosexual exposure abroad (predominantly in sub-Saharan Africa), which predominates in London, and injecting drug use (either by the woman or her sexual partner), which predominates in Scotland; both are important in the rest of the United Kingdom. ${ }^{2-10}$ Secondary analyses made were of inner versus outer London, metropolitan England (outside London) versus non-metropolitan England, and Edinburgh and Dundee versus the rest of Scotland.
See editorial by

Mercey

AIDS and Sexually

Transmitted Diseases Centre, PHLS

Communicable

Disease

Surveillance Centre, London NW9 5EQ

Angus Nicoll, consultant epidemiologist Christine McGarrigle, senior scientist Anthony R Brady, statistician Janet Mortimer, senior scientist Susan Cliffe, senior scientist

Department of Epidemiology and Biostatistics, Institute of Child Health, London WC1N 1EH

A E Ades, reader in epidemiology and biostatistics Pat Tookey, research fellow Trinh Duong, statistician Catherine Peckham, professor in epidemiology and biostatistics

Scottish Centre for Infection and Environmental Health, Ruchill Hospital, Glasgow G20 9NB

David Goldberg, deputy director continued over BMJ 1998;316:253-8 
Department of

Obstetrics and

Gynaecology,

St Bartholomew's

Hospital, London

EC1A 7BF

Chris Hudson,

emeritus professor of

obstetrics and

gynaecology

Department of

Child Health, Royal

Hospital for Sick

Children, Glasgow

G3 8SJ

David Tappin,

senior lecturer

Correspondence to:

Dr Nicoll

anicoll@phls.co.uk

Table 1 HIV-1 infection among pregnant women by area of residence. Unlinked anonymous surveys, United Kingdom, 1988-96

\begin{tabular}{|c|c|c|c|c|c|c|c|c|c|c|}
\hline & \multicolumn{9}{|c|}{ Year of birth of child } & \multirow[b]{2}{*}{ Total } \\
\hline & 1988 & 1989 & 1990 & 1991 & 1992 & 1993 & 1994 & 1995 & 1996 & \\
\hline Total tested & 31009 & 74450 & 67153 & 82678 & 106946 & 103862 & 105097 & 104501 & 104666 & 780362 \\
\hline Prevalence (\%) & 0.032 & 0.052 & 0.082 & 0.130 & 0.150 & 0.180 & 0.170 & 0.180 & 0.191 & \\
\hline \multicolumn{11}{|l|}{ Scotland } \\
\hline Prevalence (\%) & - & - & 0.029 & 0.028 & 0.032 & 0.028 & 0.029 & 0.025 & 0.025 & \\
\hline \multicolumn{11}{|l|}{ Rest of UK* } \\
\hline Total tested & 20649 & 55676 & 60948 & 126741 & 213992 & 270448 & 357713 & 346791 & 347407 & 1800365 \\
\hline No HIV-1 positive & 1 & 3 & 6 & 13 & 22 & 25 & 47 & 38 & 56 & 211 \\
\hline Prevalence (\%) & 0.005 & 0.005 & 0.010 & 0.010 & 0.010 & 0.009 & 0.013 & 0.011 & 0.016 & \\
\hline
\end{tabular}

In addition, 11741 samples $(0.380 \%)$ could not be tested because insufficient specimen remained after completion of clinical testing, and 7866 samples $(0.028 \%)$ were not tested because of objection. The sporadic occurrence of objections indicated that they were unlikely to be biasing results. ${ }^{11}$ Fifty four of the 116 participating health districts and health boards had at least one HIV-1 positive sample.

*Includes data from an antenatal survey.

\section{Prevalence (unlinked) data}

The prevalence of HIV-1 infection among pregnant women proceeding to live birth was derived from unlinked surveys using residual dried blood spot samples remaining after metabolic screening of newborn infants. The surveys began in 1988 and since 1994 have covered approximately $70 \%$ of the United Kingdom cohort of births including London and south east England, most other metropolitan areas, and all of Scotland. Details of methods, laboratory techniques, regional coverage, and completeness are described elsewhere. ${ }^{11-14}$

\section{Surveillance (linked) data}

The numbers of HIV-1 infections diagnosed in mothers and children with vertically acquired AIDS (mother to child transmission of HIV-1), their characteristics, and maternal exposure categories were based on voluntary confidential reporting by obstetricians, paediatricians, other clinicians, and microbiologists. ${ }^{13-16}$ Children with lymphoid interstitial pneumonitis as the sole AIDS defining condition were not included among those with AIDS as this condition does not indicate severe HIV disease. ${ }^{17}$

\section{Proportions of maternal HIV-1 infections diagnosed}

Estimates of the proportions of infections diagnosed before and during antenatal care were based on obstetricians' reporting of HIV infected pregnant women (surveillance data) in areas and time periods where unlinked surveys had been under way. ${ }^{15}$

Grouped logistic regression was used to examine and express time trends in HIV prevalence and the diagnosis rates of HIV-1 infected mothers over time. The data were analysed within the predefined geographical strata, and both linear and polynomial functions of time were fitted. Normalised (deviance) residuals were inspected to assess the adequacy of fitted models. All $\mathrm{P}$ values reported are two tailed.

\section{Results}

\section{Prevalence of HIV-1 in newborns}

The prevalence of HIV-1 in newborn infants (unlinked data) was determined from 3080632 blood samples. HIV-1 seropositivity was confirmed in 1459 samples $(0.047 \%)$ (table 1). Prevalence of HIV-1 rose more than fivefold among mothers resident in London, from $0.032 \%$ of women tested in 1988 to $0.19 \%$ in 1996 (fig; table 1). This rise was significant for mothers resident in inner and outer London (average odds ratio of 1.16 per year $(95 \%$ confidence interval 1.12 to 1.19$))$. Prevalence in London hardly changed between 1993 and 1996 (table 1), and there was evidence of curvature in the graph describing the rise $(\mathrm{P}<0.001)$ (fig), consistent with a slowing of the rise in London over that period. These time trends were essentially the same when the analysis was confined to the areas of London that had participated throughout the period of study. ${ }^{11}$

Overall prevalences in Scotland and the rest of the United Kingdom were low and did not change with time (fig; table 1). However, prevalence was high initially in Edinburgh and Dundee and then declined from $0.22 \%$ ( 16 of 7406 ) in 1990 to $0.088 \%$ (6 of 6810 ) in 1996, an average odds ratio for the decline of 0.88 per year (0.75 to 1.02$)$.

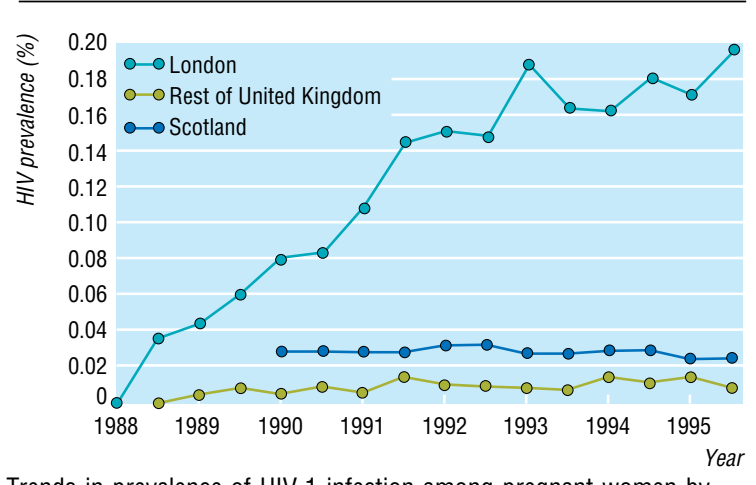

Trends in prevalence of HIV-1 infection among pregnant women by area of residence, United Kingdom, 1988-96 
A small but significant rise took place in non-metropolitan England (average annual odds ratio for rise $=1.13 ; 1.01$ to 1.26 ) from one infection among $20649(0.005 \%)$ specimens in 1988 to $0.016 \%$ (38 of 232374 ) in 1996. When data were confined to the centres that had participated from 1990 onwards the rise was still significant (odds ratio 1.19; 1.04 to 1.35 ). No significant time trends were seen in metropolitan England or Scotland outside Edinburgh and Dundee.

In 1996 the highest prevalences occurred for newborns of mothers in inner London $(0.30 \%, 132$ of $44153)$ followed by outer London $(0.11 \%, 68$ of $60513)$ and Edinburgh and Dundee $(0.088 \%, 6$ of $6810)$, where they were five times higher than in the rest of Scotland $(0.0017 \%, 9$ of 52729$)(P=0.001)$. In 1996, levels of infection in Scotland and the rest of the United Kingdom were respectively eight and 12 times lower than the level in London (table 1). Prevalence in metropolitan England outside London (0.016\%, 18 of 115 033), non-metropolitan England (0.016\%, 38 of 232 374), and the rest of Scotland (0.0017; 9 of 52 729) did not differ significantly $(\mathrm{P}=0.98)$.

It was assumed that the prevalences in the areas of the United Kingdom not included in the dried blood spot surveys ${ }^{13}$ were the same as in England outside of London and south east England. Applying the observed 1996 prevalences to the numbers of registered births gave an estimated 307 (299 to 318) live births in 1996 to HIV-1 infected women in the United Kingdom: $65 \%$ in London, $5 \%$ in Scotland, and $30 \%$ in the rest of the United Kingdom.

\section{Characteristics of mothers diagnosed as infected with HIV-1}

Surveillance (linked) data show that during 1988-96, 797 live births to HIV-1 infected mothers in the United Kingdom were reported (table 2). Mothers who had probably been infected heterosexually abroad accounted for $58 \%$ (461 births), and mothers who them- selves injected drugs (151 births) or whose partners did (59 births) accounted for another 26\%. Only 6\% of births (49) were to mothers apparently infected heterosexually in the United Kingdom by a man without a known history of high risk (table 2). Numbers of births to infected mothers in this category increased from 10 in 1988-92 to 39 in 1993-6, while numbers associated with drug injecting declined from 140 in 1988-92 to 70 in 1993-6 in the United Kingdom as a whole; in Scotland the reduction was greatest (from 67 to 33).

The distribution of maternal exposure categories for vertically acquired HIV infections that had progressed to AIDS was not subject to the biases associated with voluntary confidential HIV testing. This distribution gives the best available indication of the relative contribution of different routes of maternal infection. ${ }^{2}$ The child's ethnic group is also not affected by these biases. ${ }^{2}$ In London 89\% (83 of 93) of AIDS cases were in children born to mothers heterosexually exposed abroad, whereas in Scotland injecting drug use accounted for three of the five cases of vertically acquired paediatric AIDS. In the rest of the United Kingdom maternal heterosexual exposure abroad accounted for $50 \%(15 / 30)$ and injecting drug use for $23 \%(7 / 30)$ of cases of vertically acquired AIDS. Maternal heterosexual exposure in the United Kingdom accounted for only $5 \%(6 / 128)$ of the paediatric AIDS cases (table 2).

The child's (and hence the mother's) ethnic group was reported as black African in 351 of 797 births. After exclusion of 134 cases without ethnic group data, this represented 53\% (351/5663) of the total. The proportion was significantly higher $(68 \% ; 85$ of 126$)$ $(\mathrm{P}<0.001)$ for paediatric AIDS cases (table 3). Only 79 reported births to infected mothers (12\%) and 16 cases of AIDS (13\%) including those cases reported of mixed race were among other ethnic minority groups. Eighty nine per cent (344 of 387 with ethnic group reported) of births to mothers probably infected heterosexually

Table 2 Exposure categories for mothers diagnosed as HIV-1 infected (and children with vertically acquired AIDS*): births 1988-96 in the United Kingdom reported before the end of July $1997 \dagger$

\begin{tabular}{|c|c|c|c|c|c|c|c|c|}
\hline \multirow[b]{3}{*}{ Probable route of acquisition of mother's infection } & \multicolumn{6}{|c|}{ Mother's area of residence } & & \\
\hline & \multicolumn{2}{|c|}{ London } & \multicolumn{2}{|c|}{ Scotland } & \multicolumn{2}{|c|}{ Rest of UK } & \multicolumn{2}{|c|}{ Total } \\
\hline & $\begin{array}{c}\text { All } \\
\text { children } \\
(\mathrm{n}=324)\end{array}$ & $\begin{array}{l}\text { Children } \\
\text { with } \\
\text { AIDS } \\
(n=93)\end{array}$ & $\begin{array}{c}\text { All } \\
\text { children } \\
\text { ( } n=109)\end{array}$ & $\begin{array}{c}\text { Children } \\
\text { with } \\
\text { AIDS } \\
(n=5)\end{array}$ & $\begin{array}{c}\text { All } \\
\text { children } \\
(n=164)\end{array}$ & $\begin{array}{l}\text { Children } \\
\text { with } \\
\text { AIDS } \\
(\mathrm{n}=30)\end{array}$ & $\begin{array}{c}\text { All } \\
\text { children } \\
(\mathrm{n}=797)\end{array}$ & $\begin{array}{c}\text { Children } \\
\text { with } \\
\text { AIDS } \\
(\mathrm{n}=128)\end{array}$ \\
\hline \multicolumn{9}{|l|}{ Non-sexual route } \\
\hline \multicolumn{9}{|l|}{ Sexual intercourse between men and women } \\
\hline \multicolumn{9}{|c|}{ Exposure to high risk partner(s), presumed infected through: } \\
\hline Injecting drug use & 14 & 0 & 29 & 2 & 16 & 4 & 59 & 6 \\
\hline Blood factor treatment or blood or tissue transfer & 2 & 0 & 0 & 0 & 13 & 2 & 15 & 2 \\
\hline Sexual intercourse between men & 2 & 1 & 1 & 1 & 11 & 0 & 14 & 2 \\
\hline United Kingdom or Eire & 6 & 3 & 3 & 0 & 11 & 3 & 30 & 6 \\
\hline Other or undetermined route & 9 & 0 & 3 & 0 & 14 & 3 & 46 & 3 \\
\hline
\end{tabular}

${ }^{*}$ Acquired through mother to child transmission of HIV and excluding AIDS diagnosis based on lymphoid interstitial pneumonitis (an unreliable indicator of severe disease). ${ }^{19}$

†An additional 98 children reported as born in 1988-96 outside the United Kingdom are not included in this report.

łIncludes cases of heterosexually exposed partner from a high prevalence country.

$\S$ Countries where HIV is common and heterosexual intercourse is the predominant mode of transmission. 
Table 3 Ethnic group of children born to mothers diagnosed as HIV-1 infected and of children with vertically acquired AIDS Values are numbers (percentages) of births 1988-96 in the United Kingdom reported before the end of July 1997

\begin{tabular}{|c|c|c|}
\hline Ethnic group & All children* & $\begin{array}{l}\text { Children with vertically } \\
\text { acquired AIDS }\end{array}$ \\
\hline \multicolumn{3}{|l|}{ London } \\
\hline White & $60(14)$ & $7(8)$ \\
\hline Black African & $322(75)$ & $76(84)$ \\
\hline Other† & $23(5)$ & $4(4)$ \\
\hline Mixed race & $27(6)$ & $4(4)$ \\
\hline Total & $432(100)$ & $91(100)$ \\
\hline Not recorded & 92 & 2 \\
\hline \multicolumn{3}{|l|}{ Scotland } \\
\hline White & $97(96)$ & $3(60)$ \\
\hline Black African & $2(2)$ & $1(20)$ \\
\hline Other† & 0 & - \\
\hline Mixed race & $2(2)$ & $1(20)$ \\
\hline Total & $101(100)$ & $5(100)$ \\
\hline Not recorded & 8 & - \\
\hline \multicolumn{3}{|c|}{ Rest of United Kingdom } \\
\hline White & $76(58)$ & $14(47)$ \\
\hline Black African & $27(21)$ & $9(30)$ \\
\hline Othert & $2(2)$ & - \\
\hline Mixed race & $25(19)$ & $7(23)$ \\
\hline Total & $130(100)$ & $30(100)$ \\
\hline Not recorded & 34 & - \\
\hline \multicolumn{3}{|l|}{ Total } \\
\hline White & $233(35)$ & $24(19)$ \\
\hline Black African & $351(53)$ & $86(68)$ \\
\hline Othert & $25(4)$ & $4(3)$ \\
\hline Mixed race & $54(5)$ & $12(10)$ \\
\hline Total & $663(100)$ & $126(100)$ \\
\hline Not recorded & 134 & 2 \\
\hline
\end{tabular}

*Includes 280 children of indeterminate infection status and 267 children who were uninfected.

†Includes children reported as ethnic group Black Caribbean (14 children, 2 children with AIDS), Indian sub-continent (7 children, 2 children with AIDS), Oriental (no children), Middle East (1 child, none with AIDS) and other ethnic groups ( 3 children, none with AIDS).

abroad were in black African women. The proportion was higher for those who had progressed to AIDS (94\% $(85 / 90) ; \mathrm{P}=0.06)$. In London black African women predominated and the number of births to African mothers diagnosed as HIV-1 infected in 1993-6 was one and a half times that in 1988-92 (187 v 135) despite there being no increase in the overall proportion diagnosed (see table 4). In Scotland the numbers of births of newborns positive for HIV-1 declined and were almost entirely among white mothers, while in the rest of the United Kingdom both ethnic groups were important (table 3) and numbers remained unchanged over time (45 white and 13 black African in 1988-92; 31 white and 14 black African in 1993-6).

\section{Proportions of maternal infections diagnosed before the birth}

Between 1988 and 1996 the unlinked surveys detected 1459 births to HIV-1 infected mothers. Only 23\% (340 births) were to mothers whose infection had been reported as diagnosed before the birth. Among these, diagnosis had been made before pregnancy in 218 cases, $15 \%$ of the total. Of the 1241 births to infected mothers whose infections had not been detected previously, 122 had been diagnosed while the mother was receiving care in pregnancy, an overall antenatal detection rate of $10 \%$ (table 4 ). Antenatal detection rates were $10 \%$ in London and $7 \%$ in the rest of the United
Kingdom. Detection rates were significantly higher in Scotland, largely due to high rates in Edinburgh and Dundee. There was no evidence that detection rates changed over time in any area $(\mathrm{P}=0.91)$ (table 4). Overall in the United Kingdom in 1996 only 35 of 234 (15\%) previously undetected HIV-1 infections were diagnosed in the antenatal period; 26 of $173(15 \%)$ in London, 1 of $10(10 \%)$ in Scotland, and 8 of $50(16 \%)$ in the rest of the United Kingdom.

\section{Discussion}

\section{Trends in prevalence and mothers' routes of infection}

The continued raised prevalence of HIV-1 infection among mothers in London is disturbing, especially because HIV positive women who are aware of their infection are more likely to seek a termination, and surveillance using neonatal dried blood spots will thus tend to underestimate the absolute burden of HIV infection among women. ${ }^{18}{ }^{19}$ The high proportion of infected women who are African is apparent and justifies policies to improve HIV services for the black African community. ${ }^{3-13}$ A diminishing proportion of maternal infections attributable to injecting drugs is consistent with other indications of low rates of HIV transmission though this route. ${ }^{13-20}$ However, it is less clear how infections in other women have contributed to the rise from 1988 onwards. The data cannot exclude the possibility of a rise in prevalence among women who acquire their infection in the United Kingdom, and the extent of heterosexual HIV transmission in this group is probably underestimated in data on diagnosed infections since a woman exposed to infection both in Africa and the United Kingdom is assumed to have been infected abroad. ${ }^{21}$ Gathering data on ethnic group or country of birth (the latter is already under way in surveys of attenders of sexually transmitted diseases clinics) would greatly increase the value of the unlinked data. ${ }^{10-13}$

Though there has been no overall rise outside London, the increases in prevalence in nonmetropolitan England and in reports of births to mothers infected heterosexually in the United Kingdom indicate the importance of maintaining surveillance. Equally, intensification of HIV transmission in South Asia ${ }^{22}$ may result in HIV appearing in Asian communities in the United Kingdom, and this will also require early detection.

\section{Impact of diagnostic testing policies}

The success of the international trial of zidovudine and of other initiatives, such as discouraging breast feeding, in reducing mother to child transmission make it a matter of public health concern that the Department of Health policies to enhance antenatal voluntary confidential HIV testing ${ }^{6}$ have had so little impact. ${ }^{23}$ Increased detection in London could prevent nearly three quarters of paediatric HIV infections (estimated to be around 40 per year). ${ }^{24}$ However, only a few hospitals have begun to offer testing to all pregnant women. ${ }^{23-25}$ A selective approach in London is unlikely to be completely successful, not least because offering HIV testing only to black African women would have missed $16 \%$ (15 of 91) of women whose children developed AIDS (table 3). The new finding that more 
Table 4 Births to women with HIV-1 infection detected through unlinked anonymous surveys that were clinically diagnosed, 1988 to 1996

\begin{tabular}{|c|c|c|c|c|c|}
\hline \multirow[b]{2}{*}{ Maternal area of residence } & \multicolumn{4}{|c|}{ Year of birth } & \multirow{2}{*}{$\begin{array}{l}\text { Births to HIV-1 infected } \\
\text { women diagnosed }\end{array}$} \\
\hline & $1988-90$ & $1991-2$ & $1993-4$ & $1995-6$ & \\
\hline \multicolumn{6}{|l|}{ London } \\
\hline No $(\%)$ diagnosed before pregnancy* $(n=142)$ & $13(13)$ & $32(12)$ & $43(12)$ & $54(14)$ & $142(13)$ \\
\hline No (\%) diagnosed during pregnancy† $(\mathrm{n}=97)$ & $13(14)$ & $21(9)$ & $26(8)$ & $37(11)$ & $97(10)$ \\
\hline No (\%) diagnosed overall $(\mathrm{n}=239)$ & $26(35)$ & $53(20)$ & $69(19)$ & $91(23)$ & $239(21)$ \\
\hline No (\%) diagnosed before pregnancy* $(n=52)$ & $11(58)$ & $19(48)$ & $13(36)$ & $9(30)$ & $52(42)$ \\
\hline No $(\%)$ diagnosed during pregnancy† $(\mathrm{n}=12)$ & $3(38)$ & $1(5)$ & $6(26)$ & $2(10)$ & $12(16)$ \\
\hline No $(\%)$ diagnosed overall $(n=64)$ & $14(74)$ & $20(50)$ & $19(53)$ & $11(37)$ & $64(51)$ \\
\hline \multicolumn{6}{|l|}{ Rest of United Kingdom } \\
\hline HIV-1 positive births detected in unlinked survey $(n=211)$ & 10 & 35 & 72 & 94 & \\
\hline \multicolumn{6}{|l|}{ Total } \\
\hline HIV-1 positive births detected in unlinked survey $(n=1459)$ & 133 & 340 & 470 & 516 & \\
\hline Diagnosed before pregnancy* $(n=218)$ & $25(19)$ & $56(16)$ & $66(14)$ & $71(14)$ & $218(15)$ \\
\hline No (\%) diagnosed during pregnancy† $(\mathrm{n}=122)$ & $16(15)$ & $24(8)$ & $34(8)$ & $48(11)$ & $122(10)$ \\
\hline No $(\%)$ diagnosed overall $(n=340)$ & $41(31)$ & $80(24)$ & $100(21)$ & $119(23)$ & $340(23)$ \\
\hline
\end{tabular}

Coverage of births to HIV-1 infected mothers is incomplete due to unlinked surveys not being underway in some parts of the rest of the United Kingdom and in parts of London and Scotland in the period 1988-91. Proportion diagnosed is subject to reporting delay.

*Diagnosed before start of antenatal care.

†Derived for diagnosed during pregnancy derived by dividing reports of new diagnoses made in the antenatal period by numbers of detected births to HIV-1 infected mothers minus previously diagnosed infections.

than a third of births to infected mothers take place outside London indicates the need to implement antenatal testing elsewhere in England, though it is unclear whether a universal testing policy would be cost effective in areas of low prevalence. ${ }^{2627}$

If diagnosis rates remain low, the numbers of vertically acquired infections in the United Kingdom will increase substantially. ${ }^{28}$ Women who know they are HIV infected wish to avoid having an infected child, ${ }^{19-29}$ but to achieve this, diagnostic antenatal HIV testing must be more available and accessible, especially in London. ${ }^{27-31}$ It is unfortunate (and inequitable) that whether a mother is offered HIV testing depends on which London hospital she attends ${ }^{23}$ and which professional she sees. ${ }^{32}$ Edinburgh and Dundee are

\section{Key messages}

- HIV-1 infections among pregnant women are commonest in London but they are found in all parts of the United Kingdom

- Black African ethnic group or a history of drug injecting are important risk factors, but HIV-1 infection occurs among women without either characteristic

- Identification of HIV infection in pregnant women, if combined with uptake of interventions, reduces the risk of mother to child transmission

- HIV testing should be universally available in all antenatal clinics without any obstacle

- All pregnant women in London should be offered and recommended HIV testing; elsewhere, HIV testing should be offered and recommended to those with risk characteristics identifying higher proportions of infected women, ${ }^{27}$ and several other European countries and the United States test substantial proportions of women antenatally. ${ }^{33}$ France, where since 1993 by law all pregnant women are offered HIV testing, ${ }^{27}$ has been especially successful in reducing its rate of paediatric AIDS. ${ }^{34} \mathrm{~A}$ similar legislative approach has been undertaken in the Netherlands. ${ }^{35}$ In the United States testing and identification improved, even in inner city areas, after inter-professional guidelines were produced soon after the zidovudine trial, ${ }^{5-37}$ and the incidence of vertically acquired AIDS is declining nationally. ${ }^{38}$

Through the efforts of obstetricians, paediatricians, pathologists, and public health officials, surveillance in the United Kingdom for HIV among children and pregnant women has become highly effective. A system is in place that will provide timely detection of changes and will monitor the success or otherwise of interventions designed to reduce maternal and paediatric HIV infections.

Contributors: AN coordinated analyses and writing of the paper, developed and managed the unlinked anonymous dried blood spot survey coordinated by the Public Health Laboratory Service (PHLS), and held overall responsibility for paediatric and obstetric HIV and AIDS surveillance for the PHLS. CMcG coordinated the PHLS dried blood spot and antenatal surveys 1993-6, assembled data for the paper, and contributed to analysis and writing. SC held responsibility for surveys from mid-1996 onwards and updated the paper with 1996 data. Emma Hutchinson coordinated surveys 1993-4. ARB undertook the statistical analyses for this paper with guidance from AEA who with CP designed and developed the unlinked survey undertaken by the Institute of Child Health, London, (ICH) from 1988 onwards. AEA and CP also contributed to the analyses and writing of this paper, along with TD, and established and managed the survey of HIV in pregnancy of the Royal College of Obstetricians and Gynaecologists (RCOG) with CH. The ICH, with the PHLS Communicable Disease Surveillance Centre (CDSC) and the Scottish Centre for Environmental Health (SCIEH), initiated and undertook surveillance for HIV in 
children in the United Kingdom through the British Paediatric Surveillance (BPSU) of the Royal College of Paediatrics and Child Health (RCPCH). Collation of reports received through the BPSU, the RCOG, and laboratory HIV reporting was undertaken by PT with Janet Masters at ICH, working in collaboration with JM at CDSC and David Goldberg at SCIEH. Earlier collation was undertaken by Clare Davison and Fiona Holland (ICH). The dried blood spot surveys in Scotland were established by David Tappan, Tony Girdwood, and Forrester Cockburn and latterly were coordinated and further developed by DG (with support from Glen Codere of SCIEH), who had responsibility for HIV and AIDS surveillance in Scotland. PT, JM, ARB, and DG also contributed to analyses and writing of the paper.

Obstetric and paediatric surveillance relied on regular active reporting by members of the RCOG and the Royal College of Paediatrics and Child Health. Additional reports were made by pathologists reporting to CDSC and SCIEH. Particular contributions to obstetric and paediatric surveillance in Scotland came from Dr F Johnstone (Department of Obstetrics and Gynaecology, University of Edinburgh) and Dr J Mok (Department of Community Child Health, Edinburgh) respectively and elsewhere from Dr D Gibb (Institute of Child Health) and Professor C Hudson.

Laboratory development, quality control, and laboratory results of the unlinked surveys were provided by Dr P Mortimer, Dr J Parry, Ms J Newham, and Ms A Mahoney of the Virus Reference Division, Central Public Health Laboratory, PHLS; Dr D Cubitt and Mr S Parker of the Institute of Child Health, London; Professor R Tedder of University College London; Drs S Cameron and E Follett of the Regional Virus Laboratory, Ruchill Hospital, Glasgow; Mr R Kennedy and Dr A Girdwood, Department of Bacteriology, Stobhill Hospital, Glasgow.

The dried blood spot surveys outside London were developed with the UK Screening Laboratory Directors Advisory and Audit Group as well as other collaborators in the national unlinked anonymous HIV seroprevalence monitoring programmes. Particular contributions to the development of the surveys outside London were made by the Directors Group chairmen, Drs R Pollitt and GM Addison. The unlinked surveys were enacted in many centres with principal collaborators Ms A Brown, Department of Bacteriology, Stobhill Hospital, Glasgow; Dr G M Addison, Royal Manchester Children's Hospital; Dr R Eglin, Leeds Public Health Laboratory; Dr P Eldridge, Lewisham Hospital; Dr S Evans, Northampton General Hospital; Dr R George, Birmingham Children's Hospital; Dr A Green, Birmingham Children's Hospital; Dr D Isherwood, Royal Liverpool Children's Hospital; Dr J Kay, John Radcliffe Hospital, Oxford; Dr R Jones, Hospital for Sick Children, Great Ormond Street, London; Dr G Kudesia, Sheffield Public Health Laboratory; Dr K Mutton, Liverpool Public Health Laboratory; Dr R Pollitt, Children's Hospital, Sheffield; Ms J Selwood, Reading Public Health Laboratory; Dr R Smith, Ninewells Hospital, Dundee; Dr A Turner, Manchester Public Health Laboratory; Dr AH Wilcox and Dr J Barron, St Helier Hospital, Surrey; and Drs M Zuckerman and S Sutherland, Dulwich Public Health Laboratory.

Funding: Obstetric surveillance through the national survey of HIV in pregnancy was supported by AVERT (AIDS Education and Research Trust). Paediatric surveillance is funded by AVERT and the Department of Health. The unlinked surveys were supported by the Medical Research Council, the Department of Health for England and the Scottish Home and Health Department

Conflict of interest: None.

1 Ades AE. Serial HIV seroprevalence surveys: interpretation, design, and role in HIV/AIDS prediction.J Acquir Immune Defic Syndr 1995;9:490-9.

2 Ades AE, Parker S, Cubitt D, Davison C, Holland F, Berry T, et al. Two methods for assessing the risk-factor composition of the HIV-1 epidemic in heterosexual women: southeast England, 1988-1991. AIDS 1992;6:1031-6.

3 United Kingdom Departments of Health. HIV and AIDS health promotion: an evolving strategy. London: Department of Health, 1995.

4 Connor EM, Sperling RS, Gelber R, Kiselev P, Scott G, O'Sullivan MJ, et al. Reduction of maternal-infant transmission of human immunodeficiency virus type 1 with zidovudine treatment. $N$ Engl J Med 1994;331:1173-80

5 Rogers MF, Moseley RR, Simonds RJ, Moore JS, Gwinn M, Elsner LG, et al. US Public Health Service recommendations for human immunodeficiency virus counseling and voluntary testing for pregnant women. MMWR 1995;44:1-15.
6 Department of Health. Offering voluntary named HIV antibody testing to women receiving antenatal care. London: Department of Health, 1992

7 Scottish Office and National Health Service in Scotland Management Executive. Offering voluntary named HIV antibody testing to women receiving antenatal care. Edinburgh: Scottish Home and Health Department, 1995. 8 Pappaioanou M, Kashamuka M, Behets F. Accurate detection of maternal antibodies to HIV in newborn whole blood dried on filter paper. AIDS 1993;7:483-8.

9 Public Health Laboratory Service Communicable Disease Surveillance Centre (HIV and STD Division); Scottish Centre for Infection and Environmental Health. Unpublished quarterly surveillance tables No 30, ronmental Health. Unpublished quarterly surveillance ta
December 1995. London: CDSC/PHLS, 1995. (Typescript.)

10 Scottish Centre for Infection and Environment Health. HIV \& AIDS surveillance in Scotland: review of the epidemic to December 1994 ANSWER (AIDS News Supplement to the Weekly Report) 1995:1-104.

11 Ades AE, Parker S, Berry T, Holland FJ, Davison CF, Cubitt D, et al. Prevalence of maternal HIV-1 infection in Thames regions: results from anonymous unlinked neonatal testing. Lancet 1991;337:1562-5.

12 Tappin DM, Girdwood RWA, Follett EAC, Kennedy R, Brown AJ, Cockburn F. Prevalence of maternal HIV infection in Scotland based on unlinked anonymous testing of newborn babies. Lancet 1991;337:1565-7.

13 Unlinked Anonymous HIV Surveys Steering Group. Unlinked Anonymou. HIV Prevalence Monitoring Programme: England and Wales, data to the end of 1996.London: Department of Health, Public Health Laboratory Services, Institute of Child Health (London), 1997.

14 Gibb DM, Faulknall W, Nokes L, Appleby S, Holland FJ, Berry T, Ades AE. Coverage of routine neonatal metabolic screening in children born to women known to be HIV-1. Com Dis Rep CDR Review 1996;5:R123-4.

15 Holland FJ, Ades AE, Davison CF, Parker S, Berry T, Hjelm M, et al. Use of anonymous newborn serosurveys to evaluate antenatal HIV screening programmes. J Med Screening 1994;1:176-9.

16 Ades AE, Davison CF, Holland FJ, Gibb DM, Hudson CN, Nicoll A, et al. Vertically transmitted HIV infection in the British Isles. BMJ 1993;306:1296-9.

17 Centers for Disease Control. 1994 revised classification system for human immunodeficiency virus infection in children less than 13 of age. $M M W R$ 1994;43:1-17.

18 Boisson E, Nicoll A, Zaba B, Rodrigues LC. Interpreting HIV seroprevalence data from pregnant women. J AIDS 1996;13:434-9

19 Stephenson JM, Griffioen A, and the Study Group for the Medical Research Council Collaborative Study of Women with HIV. The effect of HIV diagnosis on reproductive experience. AIDS 1996;10:1683-7.

20 Stimson GV, Hunter GM, Donoghoe MC, Rhodes T, Parry JV, Chalmers CP. HIV-1 prevalence in community-wide samples of injecting drug users in London, 1990-1993. AIDS 1996;10:657-66.

21 Public Health Laboratory Service Aids Centre. The surveillance of HIV-1 infection and AIDS in England and Wales. Com Dis Rep CDR Review 1991;1:R51-6.

22 Lalvani A, Shastri JS. HIV epidemic in India: opportunity to learn from the past. Lancet 1996;347:1349-50.

23 MacDonagh SE, Masters J, Helps BA, Tookey PA, Ades AE, Gibb DM. Descriptive survey of antenatal HIV testing in London: policy, uptake, and detection. BMJ 1996;313:532-3.

24 Gibb DM, MacDonagh SE, Tookey PA, Duong T, Nicoll A, Goldberg D, et al. Uptake of interventions to reduce mother-to-child transmission of HIV in United Kingdom and Ireland. AIDS 1997;11:F53-8.

25 Mercey D, Helps BA, Copas A, Petruckevitch A, Johnson AM, Spencer J Voluntary universal antenatal HIV testing. Br J Obstet Gynaecol 1997;103:1129-33.

26 Department of Health. Guidelines for offering voluntary named HIV antibody testing to women receiving antenatal care. London: Department of Health, 1994.

27 Noone A, Goldberg D. Antenatal HIV testing: what now? BMJ 1997;314:1429-30.

28 Dunn DT, Nicoll A, Holland FJ, Davison CF. How much paediatric HIV infection could be prevented by antenatal HIV testing? J Med Screening 1995;2:35-40.

29 Gibb D, MacDonagh SE, Ades AE, Hudson CN, Goldberg J, Nicoll A Uptake of interventions to reduce mother-to-child transmission of HIV in UK and Eire. AIDS 1997;11:F53-8.

30 Miller R, Madge S. Routine HIV testing in antenatal care: time to move on. The Diplomate 1997;4:26-31.

31 Gibb DM, MacDonagh SE, Gupta R, Tookey PA, Peckham CS, Ades AE Factors affecting uptake of antenatal HIV testing in London: results of a multicentre study. BMJ 1998;316:000-0.

32 Jones S, Sadler T, Low N, Blott M, Welch J. Does uptake of antenatal HIV testing depend on the individual midwife? Cross sectional study. $B M$ J 1998:316:000-0.

33 European Centre for the Epidemiological Monitoring of AIDS. HIV/AIDS Surveillance in Europe-1994/96. Paris:WHO-EC Collaborating Centre on AIDS, 1996:7-82.

34 Mayaux M-J, Teglas JP, Mandelbrot L, Berrebi A, Gallais H, Matheron S, et al. Acceptability and impact of zidovudine prevention on mother to child HIV-1 transmission in France. J Pediatr (in press).

35 Van Huis M. The Dutch experience: how we approach the problems of antenatal testing. Presented at conference on women and children with HIV and AIDS, London, 10 October 1997.

36 Centers for Disease Control. Recommendations for the use of zidovudine to reduce perinatal transmission of human immunodeficiency virus. MMWR 1994:43:1-16.

37 Wiznia AA, Crane M, Lambert G, Sansary J, Harris A, Solomon L. Zidovudine use to reduce perinatal HIV type 1 transmission in an urban medical center. JAMA 1996;275:1504-6.

38 US Department of Health and Human Services. Update: perinatally acquired HIV-AIDS, United States, 1997. MMWR 1997;46:1086-92.

(Accepted 10 September 1997) 